\title{
Electrophysiological Differentiation of New Neurons in the Olfactory Bulb
}

\author{
Ottorino Belluzzi, ${ }^{1}$ Mascia Benedusi, ${ }^{1}$ James Ackman, ${ }^{2}$ and Joseph J. LoTurco ${ }^{2}$ \\ ${ }^{1}$ Università di Ferrara, Dipartimento di Biologia, Sezione di Fisiologia e Biofisica, Centro di Neuroscienze, 46-44100 Ferrara, Italy, and ${ }^{2}$ Department of \\ Physiology and Neurobiology, University of Connecticut, Storrs, Connecticut 06269
}

\begin{abstract}
The subventricular zone produces neuroblasts that migrate to the olfactory bulb $(\mathrm{OB})$ and differentiate into interneurons throughout postnatal life (Altman and Das, 1966; Hinds, 1968; Altman, 1969; Kishi et al., 1990; Luskin, 1993; Lois and Alvarez-Buylla, 1994). Although such postnatally generated interneurons have been characterized morphologically, their physiological differentiation has not been thoroughly described. Combining retroviral-mediated labeling of newly generated neurons with patch-clamp electrophysiology, we demonstrated that soon after new cells enter the layers of the olfactory bulb, they display voltage-dependent currents typical of more mature neurons. We also show that these "newcomers" express functional GABA and glutamate receptor channels, respond synaptically to stimulation of the olfactory nerve, and may establish both axodendritic and dendrodendritic synaptic contacts within the olfactory bulb. These data provide a basic description of the physiology of newly generated cells in the $\mathrm{OB}$ and show that such new cells are functional neurons that synaptically integrate into olfactory bulb circuitry soon after their arrival.
\end{abstract}

Keywords: neurogenesis; olfactory bulb; retrovirus-mediated cell lineage; patch clamp; ion channels; immunohistochemistry; stem cells; interneurons; glutamic acid; GABA

\section{Introduction}

Two regions of the mammalian forebrain, the subgranular zone (SGZ) and the subventricular zone (SVZ), continue to generate neurons after birth and into adulthood (Alvarez-Buylla and Temple, 1998). From this site of origin, "newly generated" neurons migrate to their final destination, the olfactory bulb $(\mathrm{OB})$, where they differentiate into a variety of cell types. Much is currently known concerning the mechanisms that regulate the production and migration of neurons produced in these zones; however, very little is known concerning their physiology and function. In fact, the only way to conclusively establish that postnatally generated cells become functional neurons is to make direct physiological measurements from living cells (Rakic, 2002). This kind of evidence has been provided recently for cells generated in the SGZ in adult hippocampus, where it has been shown that the new cells differentiate into functional granule cells that integrate into hippocampal circuitry (van Praag et al., 2002). For the new cells generated in the SVZ, in contrast, direct experimental evidence of functionality is more limited (Carlén et al., 2002; Carleton et al., 2003).

Obtaining recordings from neurons identified as newly generated has been primarily impeded by the difficulty of distinguishing between previously generated and newly generated neurons in

Received April 9, 2003; revised Aug. 29, 2003; accepted Sept. 24, 2003.

This work was supported by National Institutes of Health Grant MH56524 (J.J.L.), Ministero dell'Università e della Ricerca Scientifica e Tecnologica Grant PRIN2001054998_007, and a grant from Fondazione Cassa di Risparmio di Cento (0.B.).

Correspondence should be addressed to Ottorino Belluzzi, Dipartimento di Biologia, Sezione di Fisiologia e Biofisica, Via Borsari, 46-44100 Ferrara, Italy. E-mail:mk5@unife.it.

Copyright $\odot 2003$ Society for Neuroscience $\quad$ 0270-6474/03/2310411-08\$15.00/0 living brain tissue. Our experimental approach to specifically target new cells for electrophysiological analysis was to use replication incompetent recombinant retrovirus to infect newly generated neurons in the SVZ (Sanes, 1989) and genetically mark them with a version of the fluorescent reporter protein enhanced green fluorescent protein (eGFP) (Okada et al., 1999). Expression of GFP was detected using fluorescence microscopy, and positive cells in brain slices were then targeted for patch-clamp recordings. The present set of experiments demonstrates that after a few weeks of their generation, new periglomerular (PG) and granule cells acquire functional membrane properties and integrate into existing neuronal networks within the postnatal brain.

\section{Materials and Methods}

Retrovirus preparation. High titer $\left(2-5 \times 10^{8} \mathrm{cfu} / \mathrm{ml}\right)$ replicationincompetent retrovirus-encoding eGFP was synthesized using gapEGFPm4 plasmid (a gift from Dr. S. K. McConnell, Stanford University, Stanford, CA) and the 293GPG packaging cell line (a gift from Dr. R. Mulligan, Harvard University, Cambridge, MA) as described previously (Ory et al., 1996; Okada et al., 1999).

Animals and surgical procedures. Wistar rats of either sex were obtained from Harlan (S. Pietro al Natisone, Italy) and handled according to protocols approved by the campus veterinarian (University of Ferrara, Ferrara, Italy). Anesthesia was obtained by hypothermia on ice for ages up to postnatal day (P) 14 and by using ketamine $(60 \mathrm{mg} / \mathrm{kg}) / x y l a z i n e ~(8 \mathrm{mg} / \mathrm{kg})$ for older animals. A $1 \mu \mathrm{l}$ solution containing eGFP retrovirus was injected into the anterior portion of the SVZ (SVZa). The coordinates used (with respect to bregma) were the following (in $\mathrm{mm}$ ): $0.5-1.5$ anterior, 1.5 lateral, and 3.0 (young animals) or 5.0-5.5 ventral (older animals).

Immunocytochemistry. Animals were transcardially perfused with PBS followed by cold $4 \%$ paraformaldehyde. Brains were removed, postfixed overnight, and cut sagittally (50 $\mu \mathrm{m}$ sections) on a vibratome. Sections from retrovirally infected brains were blocked in 5\% NGS/0.3\% Triton 
$\mathrm{X}-100$ in PBS and then incubated in primary antibodies overnight at $4^{\circ} \mathrm{C}$. The following primary antibodies were used in this study: neuronalspecific nuclear protein (1:1000; Chemicon, Temecula, CA), mouse GAD-6 monoclonal antibody against glutamic acid decarboxylase (GAD65) (1:50; Developmental Studies Hybridoma Bank, University of Iowa, Iowa City, IA), rabbit anti-tyrosine hydroxylase (TH) (1:1000; Chemicon), mouse anti-calbindin D-28K (1:1000; Sigma, St. Louis, MO), rabbit anti-calbindin D-28K (1:1000; Swant, Bellinzona, Switzerland), mouse anti-calretinin (1:1000; Chemicon), rabbit anti-calretinin (1:1000; Swant), rabbit antisynapsin (1:500; Chemicon), mouse anti-synaptophysin (1:500; Chemicon), and rabbit anti-GFP (1:200; Chemicon). The following secondary antibodies were used: goat anti-mouse or anti-rabbit IgG-conjugated Alexa 568 (1:200; Molecular Probes, Eugene, OR) and goat anti-mouse or antirabbit IgG-conjugated Cy-5 (1:200; Jackson ImmunoResearch, West Grove, PA). Double and triple labeling of periglomerular cells was analyzed using a laser-scanning confocal microscope (TCS SP2; Leica, Nussloch, Germany), with laser lines at 488,543 , and $633 \mathrm{~nm}$. Single optical section thickness ranged from $0.5-1.0 \mu \mathrm{m}$.

Electrophysiological methods. At different times after virus injection, the rats were deeply anesthetized (injection of $60 \mathrm{mg} / \mathrm{kg}$ of sodium pentobarbital, i.p.), decapitated, the brain was exposed and chilled with oxygenated artificial CSF (ACSF), and the olfactory bulbs were dissected. Thin slices $(170-250 \mu \mathrm{m})$ were obtained by cutting the olfactory bulb in the horizontal plane, placed in the recording chamber
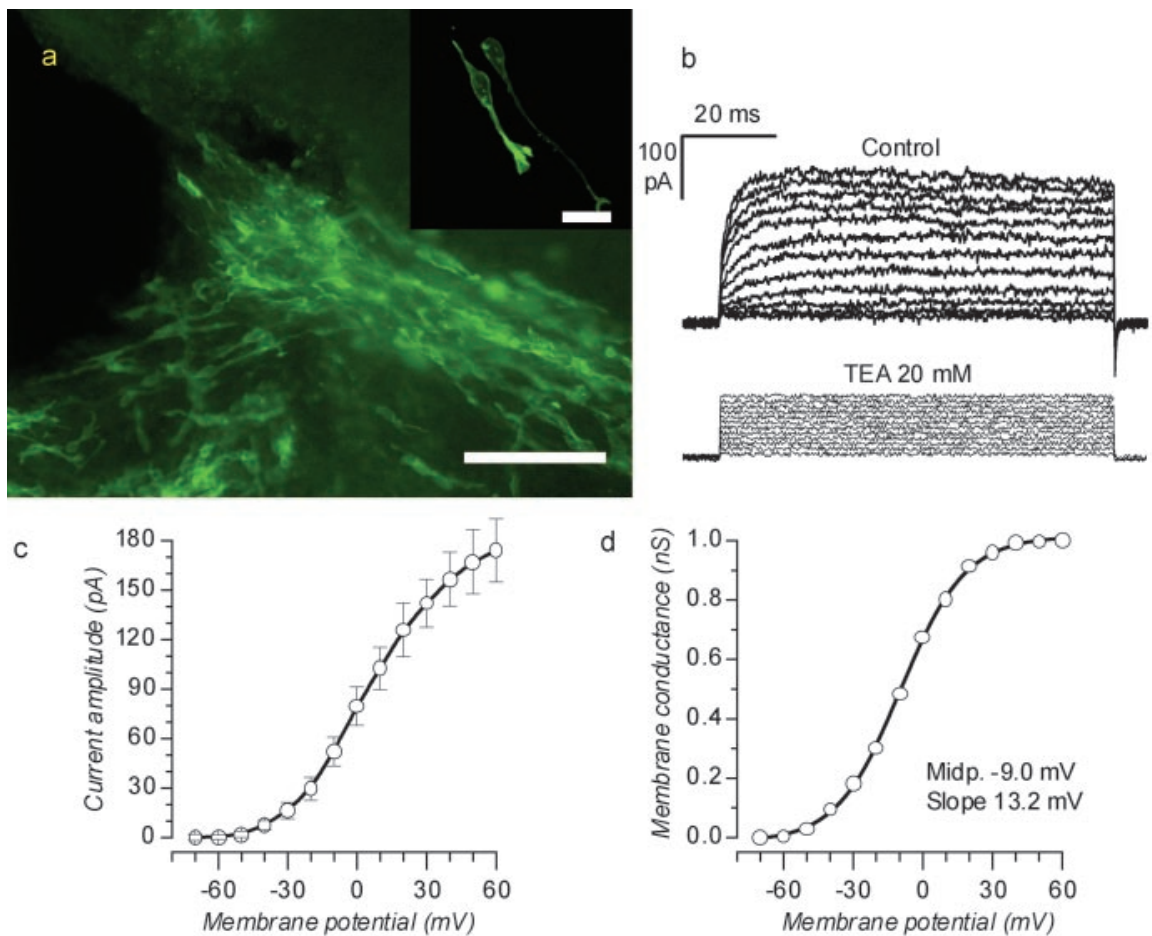

Figure 1. Morphological and electrophysiological properties of migrating neuroblasts along the RMS. a, SVZa from a rat at P89, $5 \mathrm{~d}$ after virus injection (rostral is to the right). Scale bar, $100 \mu \mathrm{m}$. The inset is a confocal image of migrating neuroblasts in the initial portion of the RMS. Scale bar, $16 \mu \mathrm{m}$. $b$, Voltage-clamp recordings from a cell in the RMS. The cell was held at $-70 \mathrm{mV}$ and depolarized to potentials ranging from -60 to $60 \mathrm{mV}$ in normal ACSF (top) and after the addition of the potassium channel blocker TEA (20 mM). $c, d$, Current-voltage $(c)$ and conductance-voltage (d) relationships of the delayed-rectifier $\mathrm{K}^{+}$current in migrating neuroblasts $(n=14)$. The voltage dependencies of $g_{\mathrm{K}}$ were described by Boltzmann equations with a midpoint and slope of -8.9 and $13.2 \mathrm{mV}$ and a maximal conductance of $1.0 \mathrm{nS}$.
( $1 \mathrm{~cm}^{3}$ volume), and mounted on an Olympus

BX50WI microscope (Olympus Optical, Tokyo, Japan). The slices were perfused at the rate of $2 \mathrm{ml} / \mathrm{min}$, with ACSF having the following composition (in mM): $125 \mathrm{NaCl}, 2.5 \mathrm{KCl}, 26 \mathrm{NaHCO}_{3}, 1.25 \mathrm{NaH}_{2} \mathrm{PO}_{4}, 2$ $\mathrm{CaCl}_{2}, 1 \mathrm{MgCl}_{2}$, and 15 glucose. Saline was continually bubbled with $95 \%$ $\mathrm{O}_{2} / 5 \% \mathrm{CO}_{2}$; the osmolarity was adjusted at $305 \mathrm{mOsm}$ with glucose. All drugs and neuroactive compounds were purchased from Tocris (Bristol, UK), except tetrodotoxin (TTX); Alomone Labs, Jerusalem, Israel) and TEA (Sigma). All substances tested were dissolved in ACSF and perfused during the entire slice preparation.

The pipette-filling solution contained the following (in mM): $120 \mathrm{KCl}$, $10 \mathrm{NaCl}, 2 \mathrm{MgCl}_{2}, 0.5 \mathrm{CaCl}_{2}, 5$ EGTA, 10 HEPES, $2 \mathrm{Na}$-ATP, 10 glucose; the osmolarity was adjusted at $295 \mathrm{mOsm}$ with glucose, and $\mathrm{pH}$ was set to 7.2 with $\mathrm{NaOH}$. Membrane currents were recorded and acquired with an Axopatch 200A amplifier (Axon Instruments, Foster City, CA), and a 12 bit A/D-D/A converter (Digidata 1200B; Axon Instruments); off-line analysis was performed using versions 7.0.1 and 8.0 of pClamp (Axon Instruments). For perforated patch recordings, we dissolved gramicidin $(2.7 \mu \mathrm{g} / \mathrm{ml}$; Sigma) in a modified intracellular solution, in which EGTA was omitted and $\mathrm{Ca}^{2+}$ concentration was raised to $3 \mathrm{~mm}$ to reveal immediately the rupture of the perforated patch.

Stimulation of primary olfactory afferents was obtained using a bipolar electrode applied in the olfactory nerve $(\mathrm{ON})$ layer. Biphasic stimuli (100/ $200 \mu$ sec duration; $0.02-0.5 \mathrm{~mA}$ amplitude) were delivered through a digital stimulus isolator unit (model 2300; A-M Systems, Carlsborg, WA). Neurotransmitters were applied using a rapid solution changer (RSC 160; BioLogic, Claix, France). Data are presented as the mean \pm SEM.

\section{Results}

\section{Retrovirus initially labels migrating neurons in the RMS}

One to $5 \mathrm{~d}$ after infection, many GFP + cells were present in the SVZ and in the rostral migratory stream (RMS) (Fig. 1a), but none were within the cell layers of the olfactory bulb. The labeled cells within the RMS exhibited features and properties of migrating neurons as elongated cell bodies with leading growth cones oriented toward the bulb (Ramon y Cajal, 1995) and a trailing process (Fig. 1a, inset) (Kishi et al., 1990; Lois and Alvarez-Buylla, 1994; Luskin, 1993; Zigova et al., 1996). Time lapse imaging of labeled cells in living brain slices indicated that they were indeed migratory neurons. Labeled cells typically displayed an initial fast-forward movement ( $\sim 60 \mu \mathrm{m} / \mathrm{hr}$ ) when the cell body would move into the leading process, the cell body would then stop and the trailing process would retract, and the leading process and growth cone would then advance again toward the olfactory bulb (average speed, $30 \mu \mathrm{m} / \mathrm{hr}$ ). In addition, immunocytochemistry of these cells indicated that they were positive for both class III $\beta$-tubulin, a marker for immature neurons that detects $\beta$-tubuline III (Lee et al., 1990), and doublecortin, a microtubule-associated protein important for neuronal migration in development (Gleeson et al., 1999).

Migrating neuroblasts exhibited only a weak delayed-rectifier $\left(I_{\mathrm{K}(\mathrm{V})}\right)$ potassium current (Fig. $1 b$, top tracings) that could be blocked by $20 \mathrm{~mm}$ TEA (Fig. 1b, bottom tracings) and did not express sodium current $\left(I_{\mathrm{Na}}\right)$ or fast transient potassium current $\left(I_{\mathrm{A}}\right)$. The current was activated at potentials more positive than $-30 \mathrm{mV}$ (Fig. 1c) and reached an amplitude of $174 \pm 19 \mathrm{pA}$ at 60 $\mathrm{mV}(n=14)$. By dividing the asymptotic currents by the driving force, we obtained the conductance-voltage relationship (Fig. $1 d$ ), which was described by a Boltzmann equation with a midpoint at $-9.0 \mathrm{mV}$, slope of $13.2 \mathrm{mV}$, and maximal value of $1.0 \mathrm{nS}$.

\section{Distribution of newly generated cells in the $\mathrm{OB}$}

Virally infected GFP + cells were apparent in the layers of the olfactory bulb $10-14 \mathrm{~d}$ after viral injection. Approximately $25 \%$ 

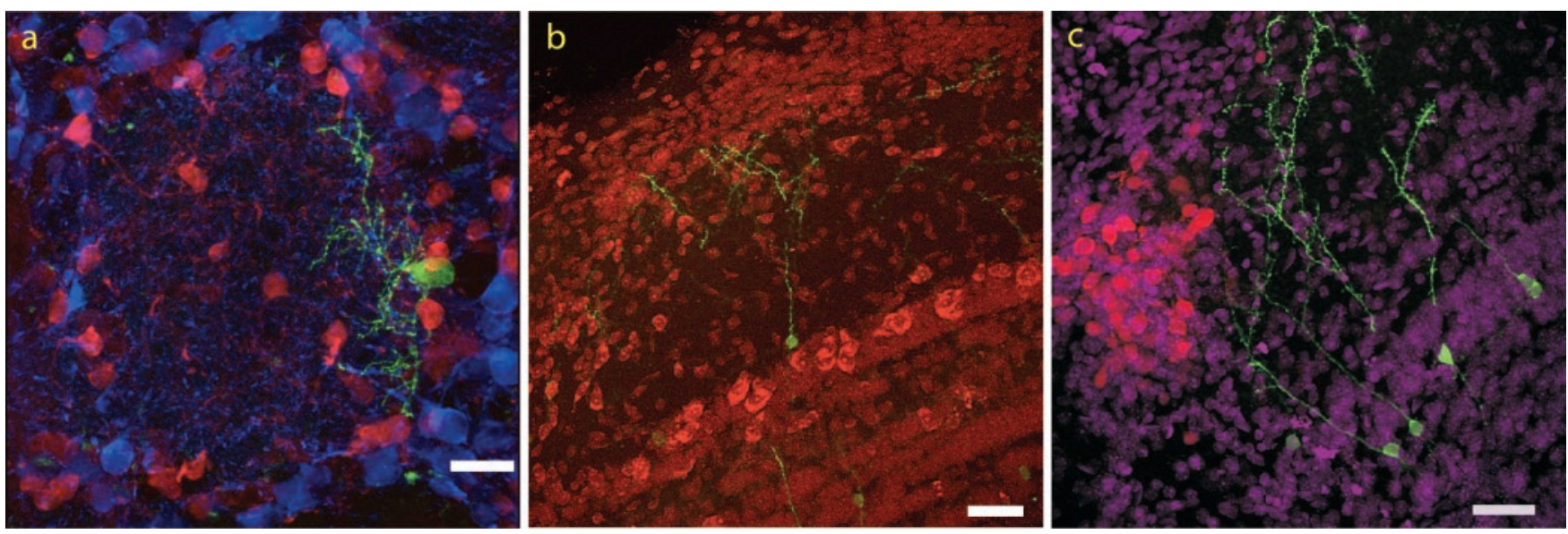

Figure 2. Newly generated cells in different layers of the olfactory bulb. $a$, A newborn eGFP+ PG cell (green) around a glomerulus at P109, 3 weeks after virus injection. Calretinin-labeled (red) and tyrosine hydroxylase-labeled (blue) PG cells outline the glomerulus. Scale bar, $20 \mu \mathrm{m} . b$, GFP + granule cell in the mitral cell layer (red, Nissl staining; P52, $37 \mathrm{~d}$ survival). Scale bar, $40 \mu \mathrm{m}$. c, GFP + cells in the granule cell layer (red, TH; magenta, TOPRO3; P52, 37 d survival). Scale bar, $40 \mu \mathrm{m}$.

of GFP + cells were dispersed in the glomerular layer, and others were found either in a narrow region encompassing the mitral cell layer and the subjacent internal plexiform layer or in the granule cell layer. The GFP+ cells in the glomerular layer had the typical morphology of PG cells: round or oval-shaped cell bodies, $4-8 \mu \mathrm{m}$, surrounding the glomeruli (Fig. 2a). Only rarely did we observe axons extending from these cells. The PG cells in the OB have distinct immunohistochemical and excitability profiles (Kosaka et al., 1995; Puopolo and Belluzzi, 1998), and we used immunocytochemistry to determine whether the new PG cells were positive for some of the major markers (Fig. 2a). Twentyfive percent of GFP + PG cells were colabeled with GAD-65, as well as $22 \%$ with calretinin and $19 \%$ with calbindin. An estimated $50 \%$ of GABAergic PG cells in adult animals is also known to be dopaminergic (Kosaka et al., 1995); thus, it was of some interest to verify the presence of colabeling of GFP with tyrosine hydroxylase. This was analyzed in four animals between P42 and P121, 26-37 d of survival. In all of these animals, we found heavy TH labeling (Fig. 2a), but we never found evidence for newly generated dopaminergic cells within the indicated temporal window.

GFP + cells localized between the mitral cell and the internal plexiform layers had oval-shaped cell bodies $\sim 15 \times 20 \mu \mathrm{m}$, a prominent dendrite ramifying in the outer third of the external plexiform layer (EPL), and short central processes branching in the granule cell layer (Fig. 2b). The labeled cells in the granule cell layer had oval-shaped somas $\sim 13 \times 20 \mu \mathrm{m}$ and prominent dendrites extending into the EPL and short central processes branching in the granule cell layer (Fig. $2 c$ ). In living slice preparations, our labeling was most intense for PG cells in the glomerular regions, thus, we focused our electrophysiological analysis on these cells.

\section{Postnatally generated cells become functional neurons}

To determine whether new PG cells become functional neurons, electrophysiological recordings were made from GFP+ cells in acute slices prepared 14-28 d after the injection of retrovirus, which was delivered on P14-P28. By P14, the olfactory bulb is fully functional with all major synaptic connections and cell layers in place; therefore, new neurons entering the bulb after this time must differentiate and form synaptic connections within primarily preestablished circuitry. Recordings from GFP + cells in the glomerular layer (117 cells) indicated that most new PG
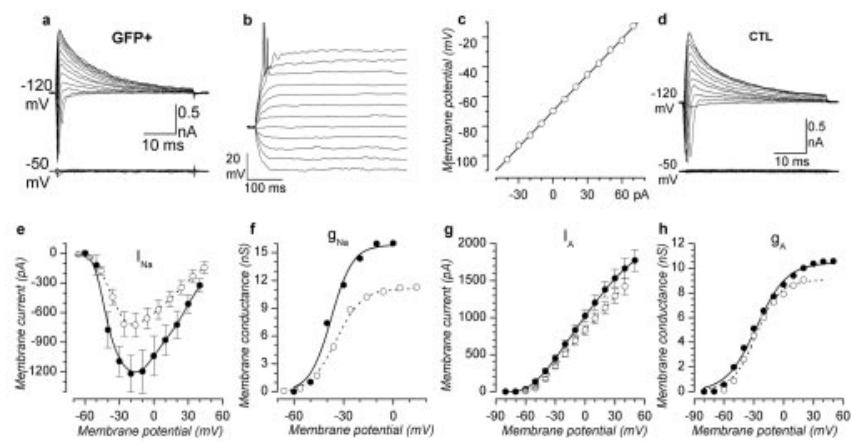

Figure 3. Properties of newborn PG cells compared with those of older neurons of the same type. $a$, Families of whole-cell currents in response to voltage steps from -50 to $80 \mathrm{mV}$ after 250 msec preconditioning at $-120 \mathrm{mV}$ (top) and $-50 \mathrm{mV}$ (bottom) (P28, $13 \mathrm{~d}$ after virus injection). $b$, Voltage responses to injected currents (from -40 to $70 \mathrm{pA}$ in steps of $10 \mathrm{pA}$ ) from a potential of $-70 \mathrm{mV}$. c, Membrane potential as a function of injected current; average potential during the last 100 msec of the depolarizing pulse. $a-c$, GFP + PG cell. $d$, Families of whole-cell currents in control PG cells in response to the same protocols as in $a . e, f, I-V$ and conductance-voltage relationships of sodium current ( $\mathrm{\text {,controls; }}, \mathrm{GFP}+$ cells). Maximal values of $g_{\mathrm{Na}}$ were $11.13 \mathrm{nS}$ in controls and $15.85 \mathrm{nS}$ in GFP + PG cells. The voltage dependencies of $g_{\mathrm{Na}}$ were described by Boltzmann equations with midpoints and slopes of -34.4 and $6.76 \mathrm{mV}$ for controls and -37.5 and $6.48 \mathrm{mV}$ for GFP + PG cells. $g, h, I-V$ and conductancevoltage relationships of $A$ current $\left(O\right.$, controls;,$G F P+$ cells). Maximal values of $g_{A}$ were 8.82 $\mathrm{nS}$ in controls and $10.5 \mathrm{nS}$ in GFP + PG cells. The voltage dependencies of $g_{\mathrm{A}}$ were described by Boltzmann equations with midpoints and slopes of -29.3 and $11.15 \mathrm{mV}$ for controls and -27.4 and $15.1 \mathrm{mV}$ for GFP + PG cells.

neurons have electrophysiological properties typical of a previously defined PG cell subtype (Puopolo and Belluzzi, 1998). Under current-clamp conditions, depolarizing current steps elicit a single action potential, followed by a plateau (Fig. $3 b$ ); the $I-V$ relationship did not show any sign of outward rectification (Fig. $3 c$ ). Consistent with the current-clamp recordings, voltageclamp recordings indicated that GFP + PG cells have inactivating inward and outward currents (Fig. $3 a$, top family of traces). The inward current was TTX sensitive $(0.3 \mu \mathrm{M})$, whereas the transient outward current was TEA (20 mM) insensitive (data not shown) and, combined with kinetic properties, identifies these currents as $I_{\mathrm{Na}}$ and $I_{\mathrm{A}}$. The absence of a significant delayed noninactivating outward $\mathrm{K}^{+}$current in these new cells can explain the absence of rectifications observed under current-clamp conditions. Depolarizations lasting $>15-20 \mathrm{msec}$ induce a complete inactivation 


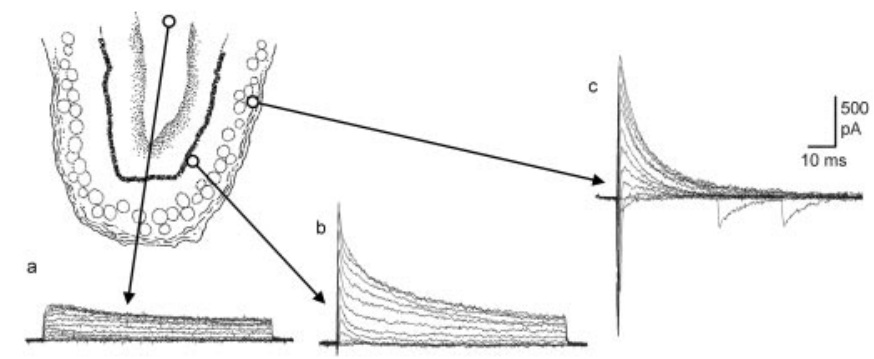

Figure 4. Maturation of voltage-dependent currents in GFP + cells. The recording from a cell in the positions is indicated by arrows. a, P32, $9 \mathrm{~d}$ survival. $b$, P28, $10 \mathrm{~d}$ survival. $c$, P31, $11 \mathrm{~d}$ survival.

of the two voltage-dependent conductances, and consequently the cells behave electrically as a resistance and capacitance in parallel with a linear $I-V$ relationship. This distinctive electrophysiology is the hallmark of a subpopulation of nonrectifying PG cells described previously (Puopolo and Belluzzi, 1998). In only four cases, we observed GFP-labeled cells in the glomerular region exhibiting noninactivating delayed-rectifier potassium currents (see below), although this is an equally prevalent physiological class of PG cells in the bulb.

The kinetic properties of $I_{\mathrm{Na}}$ and $I_{\mathrm{A}}$ in GFP + cells were determined and compared with properties of $I_{\mathrm{Na}}$ and $I_{\mathrm{A}}$ in unlabeled PG cells in the same slices. The sodium current had identical kinetics in the two cell populations, although GFP + PG cells showed a significantly larger sodium conductance (11.1 nS in controls; $15.8 \mathrm{nS}$ in GFP+ PG cells) (Fig. 3e,f). The voltage dependence of sodium conductance $\left(g_{\mathrm{Na}}\right)$ was described by a Boltzmann equation with midpoints and slopes virtually identical for unlabeled and GFP+ PG cells (Fig. 3f, legend). In contrast to the sodium current, $I_{\mathrm{A}}$ was almost identical in both kinetics and amplitude in the two cell populations, with $I-V$ and $g-V$ relationships nearly superimposing (Fig. $3 g, h$ ).

The progressive maturation of voltage-gated currents was determined by analyzing the currents present in labeled cells from the migratory route to the glomerular layer (Fig. 4). Cells in the RMS expressed only a TEA-sensitive, delayed-rectifier-type $\mathrm{K}^{+}$ current (Figs. 1b,4a). A prominent A-current was then added once cells reached the olfactory bulb, left the migratory stream, and began their radial migration toward the more external layers (Fig. 4b). The last transformation was the loss of the delayedrectifier K current and the development of a fast, TTX-sensitive $\mathrm{Na}$ current (Fig. 4c). This sequence is suggestive of a relatively rapid maturation of electrophysiological properties for newly generated cells once they enter the layers of the bulb.

In addition to PG cells with the physiology described above, we more rarely $(n=4)$ encountered GFP + cells with different electrophysiological properties in the glomerular layer (Fig. 5). These cells were characterized by an average capacity of $10.5 \mathrm{pF}$, a well developed delayed-rectifier potassium current showing a maximal conductance of $8.26 \mathrm{nS}$ and a large sodium current with a peak amplitude of $1545 \pm 327 \mathrm{pA}$ at $-20 \mathrm{mV}$ (Fig. $5 d$ ). The conductance-voltage relationship, $\mathrm{g}_{\mathrm{Na}}(V)$, could be fitted by the Boltzmann equation, with a maximal conductance of $18.3 \mathrm{nS}$, midpoint at $-39 \mathrm{mV}$, and a slope of $4.91 \mathrm{mV}$. A difference with typical periglomerular cells, under current-clamp conditions, was that these cells generated multiple action potentials in response to sustained depolarizations (Fig. 5b) and had a rather peculiar synaptic activity (see below). Morphologically, these cells showed no significant differences with PG cells but were too rare to study more thoroughly.
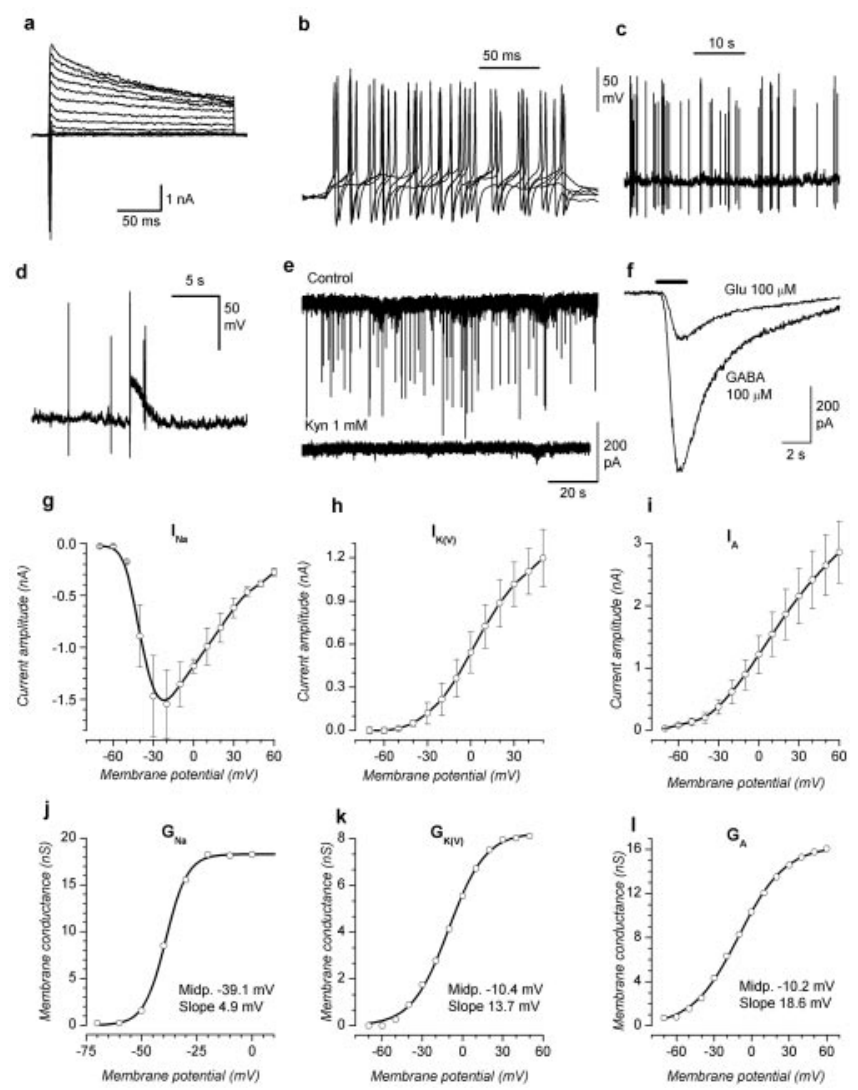

Figure 5. Electrophysiological properties of a restricted group of GFP + cells in the glomerular layer (see Results for explanation). $a$, Voltage-clamp recordings; depolarizing steps to potentials from -70 to $60 \mathrm{mV}$ after $300 \mathrm{msec}$ preconditioning to $-120 \mathrm{mV}$. b, Current-clamp responses to the injection of depolarizing current pulses showing repetitive action potentials. $c$, Spontaneous activity at rest, leading to repetitive action potentials. $d$, Giant depolarizing synaptic potentials, occasionally seen in GFP + cells.e, Spontaneous synaptic currents blocked by 1 mm kynurenate (recorded at P20, 10 d survival). $f$, Responses to focal application of GABA and glutamate (both $100 \mu \mathrm{m} ; \mathrm{P39}, 17 \mathrm{~d}$ survival). Decay time constants were 1.64 sec for GABA and 2.33 sec for glutamate. $g-i$, Current-voltage relationships for $I_{\mathrm{Na}}, I_{\mathrm{K}(\mathrm{V})}$, and $I_{\mathrm{A}} \cdot I_{\mathrm{Na}}$ was measured as peak inward current, $I_{\mathrm{K}(\mathrm{V})}$ is the asymptotic current evoked by depolarizing steps from a holding potential of $-50 \mathrm{mV}$ in the presence of $0.1 \mu \mathrm{MTTX}$, and $I_{A}$ is the peak outward current obtained by subtracting the $I_{\mathrm{K}(\mathrm{V})}$ currents from total outward currents evoked by depolarizing steps at identical potentials from a holding potential of $-120 \mathrm{mV}$. $j-l$, Conductance-voltage relationships obtained by dividing the $I-V$ data shown in $g--i$ by the corresponding driving forces. The $g-V$ relationships could be fitted by Boltzmann equations having the following parameters (amplitude, midpoint, and slope): $g_{\mathrm{Na}}, 18.3 \mathrm{nS},-39.0 \mathrm{mV}, 4.91 \mathrm{mV} ; g_{\mathrm{K}(\mathrm{V})}, 8.26 \mathrm{nS}$, $-10.4 \mathrm{mV}, 13.7 \mathrm{mV} ; g_{\mathrm{A}}, 16.7 \mathrm{nS},-10.2 \mathrm{mV}, 18.6 \mathrm{mV}$.

We also made less frequent recordings ( 14 cells) from GFP+ cells in the mitral cell-internal plexiform layers (Fig. 2b) and from cells located in the granule cell layer ( 8 cells). These cells had excitability profiles entirely different from the PG cells but similar to that described previously for mature granule cells. Under current-clamp, these cells gave repetitive spiking with increasing frequency in response to depolarizing current steps (Fig. 6a) and under voltage-clamp displayed, besides a large and fast sodium current, outward currents dominated by a TEA-sensitive weakly inactivating $\mathrm{K}^{+}$current (Fig. 6b). A kinetic analysis of these currents in the cells present in the internal plexiform layer has been performed and is illustrated in Figure $6, c-f$. The sodium current shows an $I-V$ relationship peaking at $-20 \mathrm{mV}$, with a maximal conductance of $17.5 \mathrm{nS}$, and the Boltzmann function describing the conductance-voltage relationship has a midpoint at -41.0 $\mathrm{mV}$ and a rather steep slope $(3.85 \mathrm{mV})$. The delayed-rectifier $\mathrm{K}$ current was smaller, with a maximal conductance of $9.16 \mathrm{nS}$, 

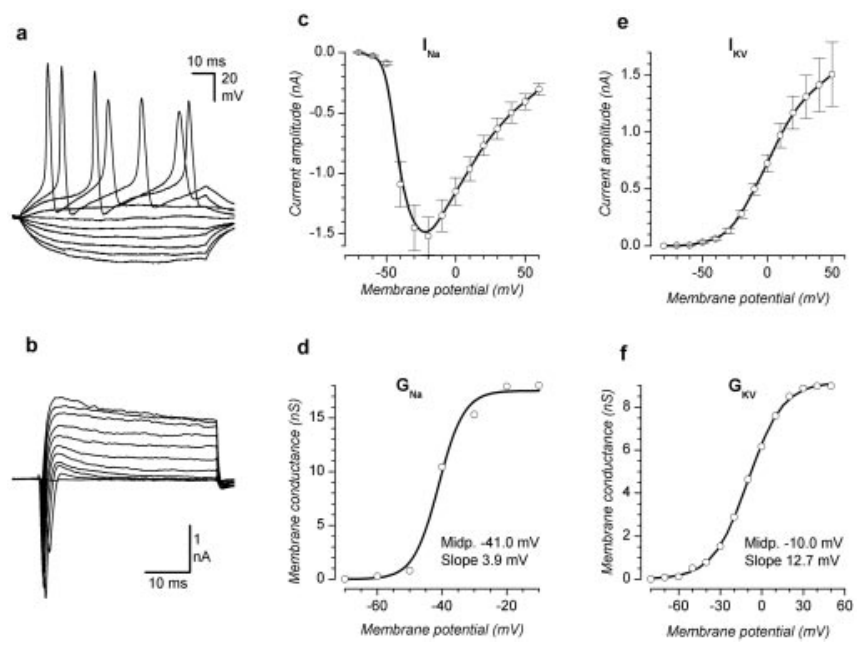

Figure 6. Electrophysiological properties of GFP + cells in the granule cell layer. $a$, Currentclamp recordings; responses to the injection of squared current pulses ranging from -50 to 40 $\mathrm{pA}$ in steps of $10 \mathrm{pA} . b$, Voltage-clamp recordings; responses to depolarizing voltage steps ranging from -70 to $30 \mathrm{mV}$ after 300 msec preconditioning at $-120 \mathrm{mV}$.c, d, Current-voltage and conductance-voltage relationships for sodium current, measured at the peak after suppression of the outward current with $20 \mathrm{~mm}$ TEA. e, f, Current-voltage and conductancevoltage relationships for delayed-rectifier potassium current, measured at the end of $40 \mathrm{msec}$ depolarizing steps.

midpoint at $-9.95 \mathrm{mV}$, and slope of $12.7 \mathrm{mV}$. Together, these results indicate that postnatally generated neurons in the $\mathrm{OB}$ attain, within days, the functional electrophysiological properties of older neurons, albeit have larger sodium currents.

\section{Maturation of functional GABA receptors and glutamate receptors}

To test for the presence of classical neurotransmitter receptorschannels in GFP + cells, we focally applied GABA and glutamate (both at $100 \mu \mathrm{M}$ ) using a rapid solution changer. GABA caused currents in all GFP + cells at all ages in postinfection survivals studied. In contrast, responses to glutamate appeared in GFP+ cells only 4 weeks after infection (Fig. $7 d$ ). Thus, functional GABA receptors develop before functional glutamate receptors in newly generated $\mathrm{OB}$ neurons.

Several important maturational changes are known to take place in the GABAergic systems during embryonic development (for review, see Owens and Kriegstein, 2002). Among these, there is a developmental shift in $E_{G A B A A}$ because of a developmental decrease in the intracellular chloride concentration, a decrease in the apparent affinity to GABA, which is reflected in greater sensitivity to GABA, and synaptic currents with slow-decay kinetics. We compared functional properties of GABA receptor-channels in $16 \mathrm{GFP}+$ and 30 unlabeled PG cells. We made whole-cell recordings using symmetrical chloride and therefore, under these conditions, we observed excitatory responses to either activation of GABAergic synapses or to direct application of this inhibitory neurotransmitter. To check the real concentration of chloride ions in newly generated cells, we performed perforated patch recordings using gramicidin, an antibiotic, creating channels that are not permeable to anions so that the intracellular chloride concentration is not perturbed. A typical experiment is shown in Figure $7, e$ and $f$. Two second applications of $100 \mu \mathrm{M}$ GABA were delivered at different resting membrane potentials under voltageclamp conditions (Fig. 7e), and the peak currents were then plotted as a function of test potentials and interpolated by a regres-

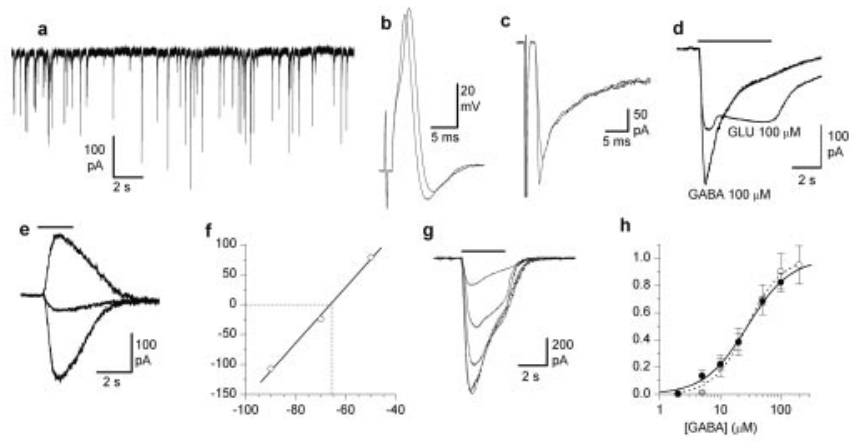

Figure 7. Synaptic properties of newly generated PG cells. $a$, Spontaneous excitatory synaptic currents in a newborn cell in the glomerular layer (P27, $12 \mathrm{~d}$ survival). This activity was blocked by picrotoxin but not by kynurenate. $b$, Action potentials in response to stimulation of the $0 \mathrm{~N}$ (P26, 12 d survival). $c$, Synaptic currents evoked by stimulation of the $0 \mathrm{~N}$ (same cell as $b$ ). Note that the delays between the stimulus artifact and the responses shown in $b$ and c suggest a monosynaptic contact between $O N$ and PG cells. $d$, Responses to focal application of $100 \mu \mathrm{M}$ GABA and $100 \mu \mathrm{m}$ glutamate in GFP + PG cells (P47, 27 d survival). e, Responses to focal GABA application $(100 \mu \mathrm{m})$ recorded under voltage-clamp conditions in gramicidin perforated patches. The three recordings were obtained at $-50,-70$, and $-90 \mathrm{mV}$, and their peak amplitudes are shown in $f$ (P47, $27 \mathrm{~d}$ survival). $f$, Linear regression of the peak responses shown in $e$, indicating a reversal potential at $-65.81 \mathrm{mV}$, corresponding to an intracellular chloride concentration of $9.75 \mathrm{~mm} . g$, Example of dose-dependent GABA-induced currents in GFP + PG cells (responses to 5, 10, 50, 100, and $200 \mu \mathrm{M}$ ). $h$, GABA dose-response curves for GFP + and control PG cells $\left(O\right.$, controls;, $\mathrm{GFP}+$ cells). $\mathrm{EC}_{50}$ were 28 and $27.7 \mu \mathrm{m}$, and the Hill coefficients were 1.55 and 1.23 for controls and GFP + cells, respectively.

sion line (Fig. $7 f$ ). The results show that at $24 \mathrm{~d}$ after injection, the reversal for GABA-induced $\mathrm{Cl}^{-}$currents is $-61.0 \pm 4.7 \mathrm{mV}$, corresponding to an intracellular chloride concentration of 11.83 $\mathrm{mm}(n=5)$.

The sensitivity of GABAergic receptors in controls and GFP+ cells has been compared (Fig. $7 g, h$ ). Two second GABA pulses at concentrations ranging from $2-200 \mu \mathrm{M}$ were applied under voltage-clamp conditions in whole-cell recordings using symmetrical chloride. Five GFP + cells and 13 controls were used for this study, showing virtually no difference in the sensitivity of the responses of the two groups. Two nearly coincident sigmoid concentration-effect curves were obtained for controls and GFP + PG cells, providing a measure of 28.0 and $27.7 \mu \mathrm{M}$ for a $50 \%$ effective concentration of GABA and Hill coefficients of 1.55 and 1.23, respectively. Finally, the kinetics of GABA currents in unlabeled and GFP + PG cells was similar. GABA responses showed a rapid desensitization (Figs. $5 f, 7 d$ ) that was similar in amplitude $(73.3 \pm 1.36$ and $79.9 \pm 2.0 \%$; measured at the end of $10 \mathrm{sec}$ application) and time constant $(2.22 \pm 0.22$ and $2.46 \pm$ $0.32 \mathrm{sec}$ ) in control and GFP + PG cells, respectively.

\section{Postnatally generated cells form functional synaptic contacts within the $\mathrm{OB}$}

To determine whether newly added PG cells receive synaptic input, we used both electrophysiology (Fig. 7) and confocal microscopy (Fig. 8). Synapsin- and synaptophysin-positive presumptive presynaptic terminals were found adjacent to GFP + dendrites in PG cells. Figure $8 a$ shows a typical example of a GFP + PG cell with synapsin-positive puncta closely adjacent to many dendritic processes. Similarly, the orthogonal projection indicates that the synapsin and PG cell dendrite are in close association.

A prominent feature of olfactory bulb circuits is reciprocal dendrodendritic synapses among interneurons and projection neurons. The PG cells are known not only to receive excitatory synaptic inputs but also to generate inhibitory synaptic outputs at 
the dendritic level. In Figure $8 b$, we show a PG cell in a 121-d-old animal in which the virus was injected at P87. The synaptic marker in this case is the vesicle protein synaptic vesicle glycoprotein 2 (SV2) (Fig. 8 , red). The insets show strong colocalization (Fig. 8, yellow) of the marker with GFP. Note that in Figure 8b1, the synapse may actually be a dendrodendritic one; arrowheads point to SV2 labeling within the dendrite terminal and just outside it, with a faint gap that is barely perceptible, dividing the two regions.

To directly test for functional synaptic contacts, we used electrophysiological measurements. We assayed for both spontaneous and stimulus-evoked postsynaptic currents from GFP + cells in the glomerular layer. Fast spontaneous excitatory synaptic currents (Fig. 7a) were observed in 13 of 113 GFP + PG cells, and these synaptic currents displayed a fast onset (average, $0.72 \pm 0.024 \mathrm{msec} ; 10-90 \%$ rise time) and a slower exponential decay (11.5 \pm 0.5 $\mathrm{msec}$ ) typical of postsynaptic responses mediated by ligand-gated channels. Up to 3-4 weeks after injection, these currents were fully and reversibly blocked by picrotoxin $(100 \mu \mathrm{M})$, whereas at longer times after virus injection, we observed the appearance of spontaneous activity blocked by the broad-spectrum glutamatergic antagonist kynurenate (1 mM). In addition to spontaneous synaptic activity, stimulation of the olfactory nerve indicated that GFP+ PG cells formed functional synapses within the olfactory bulb circuitry. Stimulation of the olfactory nerve, which directly and through the apical dendrites of projection neurons can induce synaptic excitation of PG cells, elicited synaptic responses in 20 of 52 stimulated cells. In five cells, the synaptic responses were large enough to evoke action potentials (Fig. $7 b$ ).

In contrast to the synaptic properties of most GFP+ PG cells, three of four GFP + cells in the glomerular layer exhibiting the more rare electrophysiological profile (see above) showed highfrequency spontaneous synaptic activity (Fig. 5e), often triggering action potentials in current-clamp conditions (Fig. $5 c, d$ ). These fast synaptic currents, averaging $240 \pm 89 \mathrm{pA}$, were blocked by kynurenate and not by bicuculline (Fig. $5 e$ ). Two of these cells gave a large response to the direct application of glutamate $(100 \mu \mathrm{M})$ (Fig. $5 f)$, although they were recorded at only 2 weeks after injection, a period which was approximately the time required to migrate from the $S V Z$ to the $O B$. In addition, these cells occasionally displayed giant depolarizing synaptic potentials (Fig. 5d), a common feature of newborn neurons in the hippocampus, which usually disappear after P12 (Ben-Ari et al., 1989) and in our case were observed at P27, $17 \mathrm{~d}$ after virus injection.

Our investigation of the synaptic contacts onto GFP + cells in the mitral cell-internal plexiform layer and in the granule cell layer has been less extensive. Nevertheless, in two of $20 \mathrm{GFP}+$
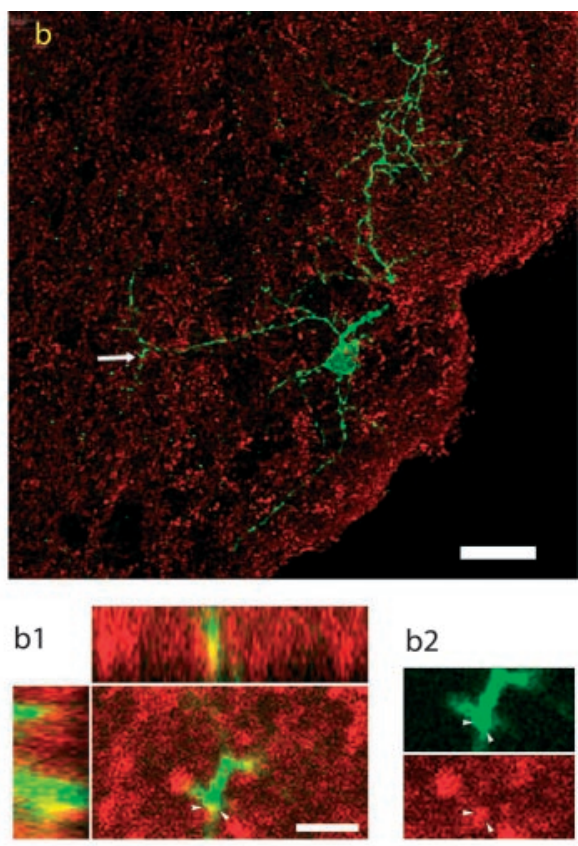

Figure 8. Immunohistochemical evidence of the presence of synaptic contacts in a newly generated PG cell. $a$, Confocal images combined to produce a three-dimensional reconstruction of a synapse on a newborn neuron. The GFP + PG cell shown (green) is " $x-z$ " by the crossed lines. The image consists of 22 optical sections, each section being $0.9 \mu \mathrm{m}$ thick. Scale bar, $8 \mu \mathrm{m}$. An enlargement 列 marker with GFP. Note that in $b 1$ the synapse may actually be a dendrodendritic one. Arrowheads point to SV 2 labeling within and (n) glutamate receptor GluR1 subunit (red) in a GFP + PG cell (green); coexpression is indicated in yellow. Confoca inages combined to produce a maximum intensity projection of a newborn neuron (inset). The PG cell shown is from a P52 anima ( $37 \mathrm{~d}$ survival). The center image is a two-channel single-optical section overlay with orthogonal $x-z$ and $y-z$ views along the indicated lines. The image consists of 24 optical sections, each section being $1 \mu \mathrm{m}$ thick. Scale bar, $20 \mu \mathrm{m}$.

cells in these layers, we observed spontaneous synaptic activity reversibly blocked by kynurenate, and in 1 of 12 cells direct stimulation of the olfactory nerve elicited a fast synaptic current.

\section{Discussion}

Until recently, only morphological (Kishi, 1987; Luskin, 1993) and immunohistochemical studies (De Marchis et al., 2001; Petreanu and Alvarez-Buylla, 2002) supported the idea that cells generated in the SVZ in adulthood become olfactory bulb interneurons. Lack of direct functional evidence left open the possibility that these newly generated neurons never fully integrate into the bulbar network. We made a kinetic characterization of the different voltage-dependent currents in the different types of newly generated interneurons and compared the properties of GFP + PG cells with previous extensive studies on control cells of the same types (Puopolo and Belluzzi, 1996, 1998). Finally, for the first time, we demonstrate that newly generated PG cells receive synaptic input from the olfactory nerve and have some elements of the presynaptic molecular machinery, suggesting that newly generated cells not only receive synaptic inputs but may 
also be presynaptic to other bulbar neurons. These data suggest that newly produced interneurons could contribute to the function of the olfactory bulb soon after their migration into the relevant layers of the mature bulb.

At the time this study was under consideration, a similar study was published showing that newly generated cells in the adult mouse olfactory bulb quickly become functional neurons that receive functional synaptic inputs from other bulbar neurons (Carleton et al., 2003). Our results in a different mammalian species (rat) and primarily focused on a different type of interneuron (periglomerular cells instead of granule cells) primarily agree with the results of Carleton et al. (2003), although some differences do exist, which are discussed below.

\section{Electrophysiological differentiation of new neurons in the bulb}

The present analysis shows that within 2 weeks after generation, newly generated neurons in the rat brain acquire electrophysiological properties typical of fully functional neurons. All labeled cells within the layers of the bulb fired action potentials and had well developed voltage-gated sodium and potassium conductances, whereas migrating cells in the RMS do not fire action potentials and have a different complement of voltage-gated conductances, primarily a TEA-sensitive delayed-rectifier potassium conductance. This indicates that the morphological and functional differentiation of PG cells occurs rapidly and nearly concurrently within the glomerular layer. A similar sequence of events has been observed in the mouse (Carleton et al., 2003), although the time required by migrating neuroblasts to cover the distance from the SVZ to the olfactory bulb is $\sim 6 \mathrm{~d}$ in the mouse, probably because of the shorter rostral migratory stream, contrary to the $10-12 \mathrm{~d}$ required in the rat.

An interesting aspect of the electrophysiological properties of newly generated cells, both periglomerular and granule cells, is that they tend to have a sodium current that is significantly larger than that in controls, with a steeper conductance-voltage relationship and more negative activation voltages. This difference, as well as the higher $g_{\mathrm{Na}} / g_{\mathrm{K}}$ ratio in new cells, may result in greater excitability to better respond to immature excitatory synaptic inputs.

\section{Electrophysiological subtype and maturational state}

Although all GFP-labeled PG cells in this study were found to be functional neurons, there appears to be an electrophysiological difference between the population of labeled and unlabeled PG cells. In a previous large-scale study of PG cells recorded randomly from the bulb, we found that $\sim 50 \%$ of PG cells have a pronounced delayed-rectified potassium current, whereas $50 \%$ have a pronounced transient, $I_{\mathrm{A}}$, potassium current without a substantial delayed-rectifier current. In the present study, 113 of 117 GFP PG cells (i.e., cells $<3$ weeks of age) had a prominent early transient potassium current and very little delayed rectifier. If new cells do in fact represent a distinct electrophysiological class, this suggests that newly added neurons to the bulb may have a specific role within the bulb. The larger implication for bulb function is not clear at this point; however, the specificity of the physiological type suggests that new neurons may be more critical to some aspects of bulb functioning than to others (Gheusi et al., 2000). In addition, because the GFP-labeled cells are expected to be younger, on average, than the unlabeled or randomly selected cells, functional differences may be related to cell age and not strictly to cell type. Because the bulb continually receives new cells throughout life, the distribution of interneurons with differ- ent physiological properties may be dynamic and regulated by the amount of new neurogenesis.

Two previous studies, one using bromodeoxyuridine (BrdU) in $\mathrm{P} 2$ neonatal rats combined with immunocytochemistry for $\mathrm{TH}$ and another using BrdU in adult mice that carry a transgene reporter for dopaminergic cells (Baker et al., 1988, 2001), have indicated that dopaminergic PG cells are generated postnatally. In contrast, we did not observe PG cells that were positive for both GFP and TH in our experiments $(n=4)$. The diversity may be explained by several differences in the studies, including the relatively small number of cells we tested for $\mathrm{TH}$ positivity, the generally longer survival times used in the previous studies (perhaps allowing for full dopaminergic maturation), species and age differences, and differences in cell populations labeled by BrdU and retrovirus injections.

\section{Synaptic integration of new neurons}

We found clear evidence of functional synaptic contacts in approximately one-half of new PG cells tested, and, for the first time, we show that neurons generated in adulthood show synaptic responses after stimulation of the olfactory nerve. Although this shows that many new cells may functionally integrate with existing bulb circuitry, it also suggests that some new cells are blocked or delayed in connecting to existing synaptic circuitry. As many new cells appear to die and are replaced throughout postnatal life (Petreanu and Alvarez-Buylla, 2002), one possibility is that new cells compete for synaptic contacts, and those that do not receive such contact may eventually die.

A notable feature of olfactory bulb circuits is reciprocal dendrodendritic synapses among interneurons and projection neurons, excitatory toward PG cells and inhibitory in the backward direction (Price and Powell, 1970; Pinching and Powell, 1971). Consistent with new PG cells forming dendrodendritic synapses, we found synaptic presynaptic proteins SV2 and synaptophysin within the dendrites of new PG cells. Together with the presence of GABAergic postsynaptic responses in new PG cells, this suggests that new PG cells may form reciprocal synapses.

The first synapses made onto new cells are GABAergic, followed only by several weeks (typically 4 weeks) by glutamatergic synapses. This is in good agreement with the observations of Carleton et al. (2003) in mouse glomerular cells. Although in migrating neuroblasts, we observed a $100 \%$ response to GABA and $0 \%$ to glutamate, instead of 73 and $29 \%$, respectively, in the mouse. A similar pattern of synaptic development has been described previously for CA1 pyramidal neurons (Ben-Ari et al., 1989; Tyzio et al., 1999). It is likely that different sets of conditions are required for the establishment of functional GABA and glutamate synapses, the latter necessitating more developed neurons, and possibly cells that have already undergone the chloride switch (Ben-Ari, 2002).

The sequence of the development of voltage-dependent currents and synaptic connections marks the major difference between our observations on newly generated PG cells and those of Carleton et al. (2003) in granule cells. In PG cells, the maturation of voltage-dependent sodium current, and consequently the capacity of the newly generated cells to fire action potentials, seems to precede the appearance of synaptic contacts, whereas in granule cells, a full development of the sodium current is observed only after the establishment of synaptic connections. This difference may indicate that the pattern of functional integration of new neurons is cell-type specific.

In future studies using bicistronic viral vectors to express both GFP and candidate genes in newly generated cells, we will be able 
to test hypotheses concerning the molecular mechanisms that regulate efficient electrophysiological differentiation and synaptic integration of new neurons. Understanding these mechanisms may be critical to future strategies of neuronal repair.

\section{References}

Altman J (1969) Autoradiographic and histological studies of postnatal neurogenesis. IV. Cell proliferation and migration in the anterior forebrain, with special reference to persisting neurogenesis in the olfactory bulb. J Comp Neurol 137:433-458.

Altman J, Das GD (1966) Autoradiographic and histological studies of postnatal neurogenesis. I. A longitudinal investigation of the kinetics, migration and transformation of cells incorporating tritiated thymidine in neonate rats, with special reference to postnatal neurogenesis in some brain regions. J Comp Neurol 126:337-389.

Alvarez-Buylla A, Temple S (1998) Stem cells in the developing and adult nervous system. J Neurobiol 36:105-110.

Baker H, Towle AC, Margolis FL (1988) Differential afferent regulation of dopaminergic and GABAergic neurons in the mouse main olfactory bulb. Brain Res 450:69-80.

Baker H, Liu N, Chun HS, Saino S, Berlin R, Volpe B, Son JH (2001) Phenotypic differentiation during migration of dopaminergic progenitor cells to the olfactory bulb. J Neurosci 21:8505-8513.

Ben-Ari Y (2002) Excitatory actions of GABA during development: the nature of the nurture. Nat Rev Neurosci 3:728-739.

Ben-Ari Y, Cherubini E, Corradetti R, Gaiarsa JL (1989) Giant synaptic potentials in immature rat CA3 hippocampal neurons. J Physiol (Lond) 416:303-325.

Carlén M, Cassidy RM, Brismar H, Smith GA, Enquist LW, Frisen J (2002) Functional integration of adult-born neurons. Curr Biol 12:606-608.

Carleton A, Petreanu LT, Lansford R, Alvarez-Buylla A, Lledo PM (2003) Becoming a new neuron in the adult olfactory bulb. Nat Neurosci 6:507-518.

De Marchis S, Fasolo A, Shipley M, Puche A (2001) Unique neuronal tracers show migration and differentiation of SVZ progenitors in organotypic slices. J Neurobiol 49:326-338.

Gheusi G, Cremer H, McLean H, Chazal G, Vincent JD, Lledo PM (2000) Importance of newly generated neurons in the adult olfactory bulb for odor discrimination. Proc Natl Acad Sci USA 97:1823-1828.

Gleeson JG, Lin PT, Flanagan LA, Walsh CA (1999) Doublecortin is a microtubule-associated protein and is expressed widely by migrating neurons. Neuron 23:257-271.

Hinds JW (1968) Autoradiographic study of histogenesis in the mouse olfactory bulb. II. Cell proliferation and migration. J Comp Neurol 134:305-322.

Kishi K (1987) Golgi studies on the development of granule cells of the rat olfactory bulb with reference to migration in the subependymal layer. J Comp Neurol 258:112-124.

Kishi K, Peng JY, Kakuta S, Murakami K, Kuroda M, Yokota S, Hayakawa S, Kuge T, Asayama T (1990) Migration of bipolar subependymal cells, precursors of the granule cells of the rat olfactory bulb, with reference to the arrangement of the radial glial fibers. Arch Histol Cytol 53:219-226.

Kosaka K, Aika Y, Toida K, Heizmann CW, Hunziker W, Jakobowitz DM, Nagatsu I, Streit P, Visser TJ, Kosaka T (1995) Chemically defined neuron groups and their subpopulations in the glomerular layer of the rat main olfactory bulb. Neurosci Res 23:73-88.

Lee MK, Tuttle JB, Rebhun LI, Cleveland DW, Frankfurter A (1990) The expression and posttranslational modification of a neuron-specific betatubulin isotype during chick embryogenesis. Cell Motil Cytoskeleton $17: 118-132$.

Lois C, Alvarez-Buylla A (1994) Long-distance neuronal migration in the adult mammalian brain. Science 264:1145-1148.

Luskin MB (1993) Restricted proliferation and migration of postnatally generated neurons derived from the forebrain subventricular zone. Neuron 11:173-189.

Okada A, Lansford R, Weimann JM, Fraser SE, McConnell SK (1999) Imaging cells in the developing nervous system with retrovirus expressing modified green fluorescent protein. Exp Neurol 156:394-406.

Ory DS, Neugeboren BA, Mulligan RC (1996) A stable human-derived packaging cell line for production of high titer retrovirus/vesicular stomatitis virus G pseudotypes. Proc Natl Acad Sci USA 93:11400-11406.

Owens DF, Kriegstein AR (2002) Is there more to GABA than synaptic inhibition? Nat Rev Neurosci 3:715-727.

Petreanu L, Alvarez-Buylla A (2002) Maturation and death of adult-born olfactory bulb granule neurons: role of olfaction. J Neurosci 22:6106-6113.

Pinching AJ, Powell TPS (1971) The neuropil of the glomeruli of the olfactory bulb. J Cell Sci 9:347-377.

Price JL, Powell TPS (1970) The synaptology of the granule cells of the olfactory bulb. J Cell Sci 764:125-155.

Puopolo M, Belluzzi O (1996) Sodium current in periglomerular cells of rat olfactory bulb in vitro. NeuroReport 7:1846-1850.

Puopolo M, Belluzzi O (1998) Functional heterogeneity of periglomerular cells in the rat olfactory bulb. Eur J Neurosci 10:1073-1083.

Rakic P (2002) Adult neurogenesis in mammals: an identity crisis. J Neurosci 22:614-618.

Ramon y Cajal S (1995) Histology of the nervous system of man and vertebrates, Vol 2 (Swanson SW, ed). Oxford: Oxford UP.

Sanes JR (1989) Analysing cell lineage with a recombinant retrovirus. Trends Neurosci 12:21-28.

Tyzio R, Represa A, Jorquera I, Ben-Ari Y, Gozlan H, Aniksztejn L (1999) The establishment of GABAergic and glutamatergic synapses on CA1 pyramidal neurons is sequential and correlates with the development of the apical dendrite. J Neurosci 19:10372-10382.

van Praag H, Schinder AF, Christie BR, Toni N, Palmer TD, Gage FH (2002) Functional neurogenesis in the adult hippocampus. Nature 415:1030-1034.

Zigova T, Betarbet R, Soteres BJ, Brock S, Bakay RA, Luskin MB (1996) A comparison of the patterns of migration and the destinations of homotopically transplanted neonatal subventricular zone cells and heterotopically transplanted telencephalic ventricular zone cells. Dev Biol 173 459-474. 